Corrigendum

\title{
Corrigendum to "A Note on the Use of Generalized Sundman Anomalies in the Numerical Integration of the Elliptical Orbital Motion"
}

\author{
José Antonio López Ortí, ${ }^{1}$ Francisco José Marco Castillo, ${ }^{1}$ and María José Martínez Usó ${ }^{2}$ \\ ${ }^{1}$ Departamento de Matemáticas, Instituto de Matemáticas y Aplicaciones de Castellón, Universidad Jaume I de Castellón, \\ 12071 Castellón, Spain \\ ${ }^{2}$ Departamento de Matemática Aplicada, Universidad Politécnica de Valencia, 46022 Valencia, Spain \\ Correspondence should be addressed to José Antonio López Ortí; lopez@mat.uji.es \\ Received 1 February 2016; Accepted 15 February 2016 \\ Copyright (C) 2016 José Antonio López Ortí et al. This is an open access article distributed under the Creative Commons Attribution \\ License, which permits unrestricted use, distribution, and reproduction in any medium, provided the original work is properly cited.
}

In the paper entitled "A Note on the Use of Generalized Sundman Anomalies in the Numerical Integration of the Elliptical Orbital Motion" [1], caption of Table 2 must be "Optimal $\alpha$ for $e,|\Delta \vec{r}|$ in $\mathrm{Km}$ and $|\Delta \vec{v}|$ in $\mathrm{Km} / \mathrm{s."}$

\section{References}

[1] J. A. López Ortí, F. J. Marco Castillo, and M. J. Martínez Usó, "A note on the use of generalized Sundman anomalies in the numerical integration of the elliptical orbital motion," Abstract and Applied Analysis, vol. 2014, Article ID 691926, 8 pages, 2014. 


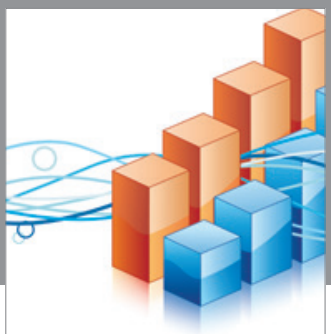

Advances in

Operations Research

vatem alat4

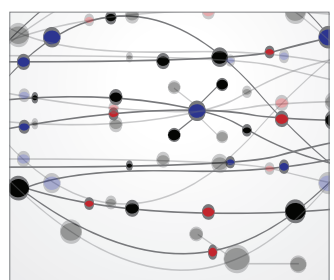

\section{The Scientific} World Journal
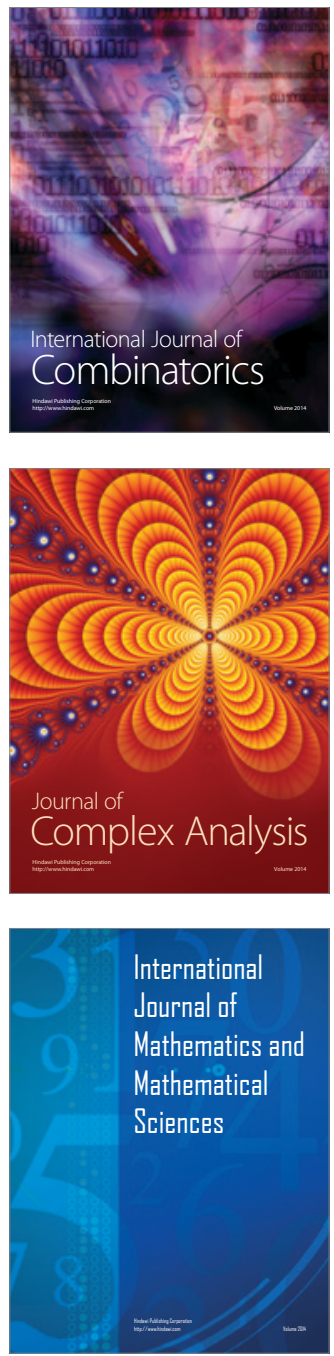
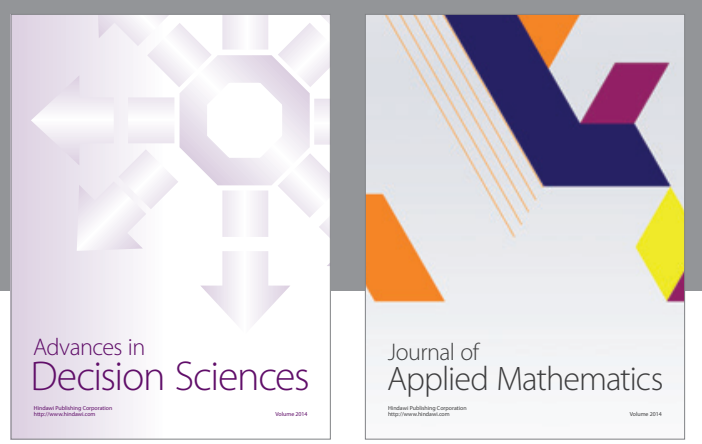

Algebra

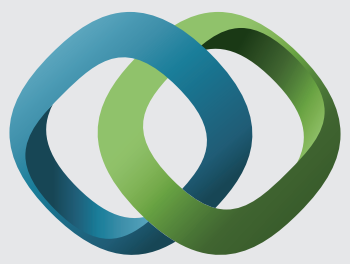

\section{Hindawi}

Submit your manuscripts at

http://www.hindawi.com
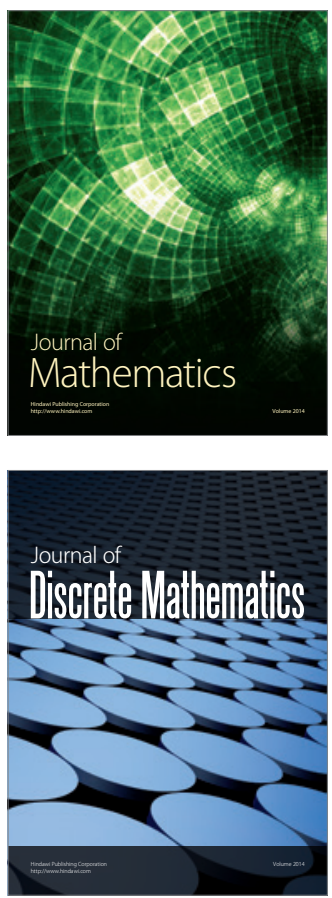

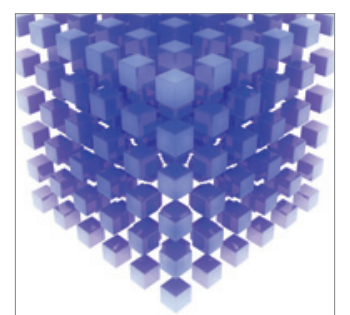

Mathematical Problems in Engineering
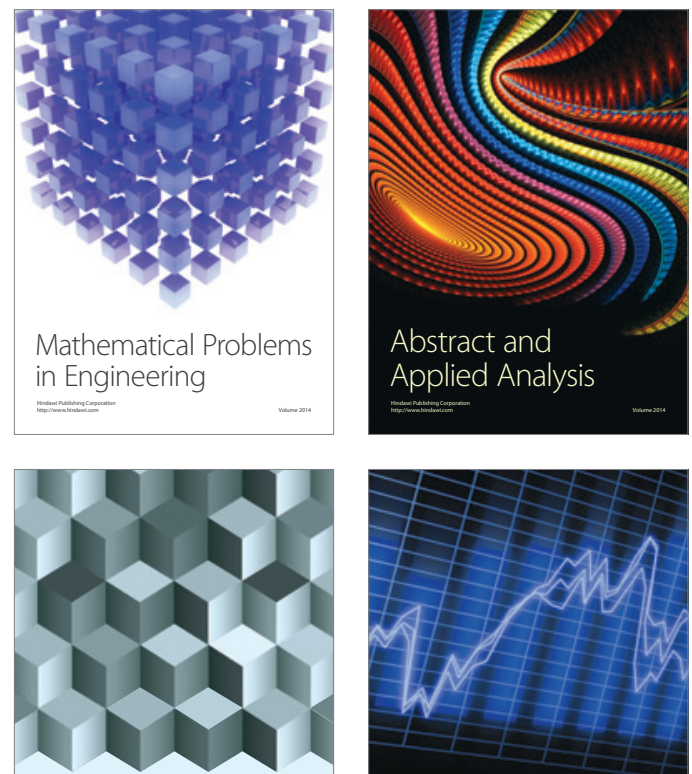

Journal of

Function Spaces

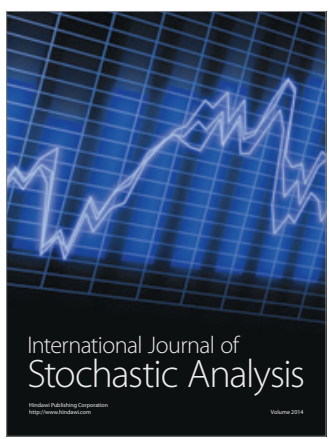

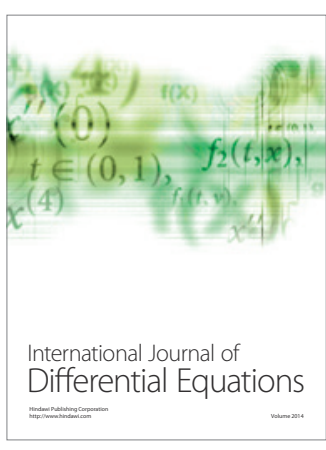
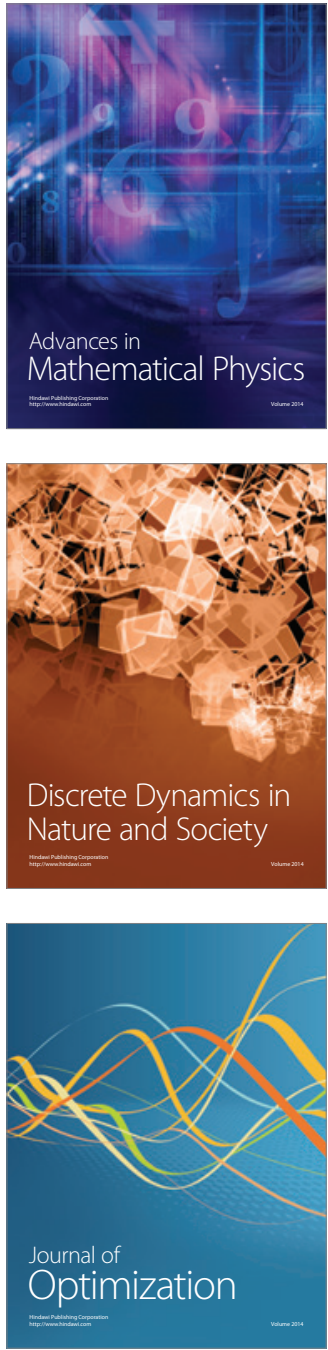